\title{
Steady State Operation of a Continuous Culture at Maximum Growth Rate by Control of Carbon Dioxide Production
}

\author{
By T. G. WATSON \\ Laboratory of Microbiology, Gulbenkian Institute of Science, Oeiras, Portugal
}

(Accepted for publication I August 1969)

\begin{abstract}
SUMMAR Y
Micro-organisms can be grown in continuous culture at maximum specific growth rate $\left(\mu_{\max }\right)$ by a new method based on control through carbon dioxide production. A carbon dioxide analyser regulates, through a controller unit, the supply of medium to the culture. Unlike the turbidostat, the new method allows almost indefinite, uninterrupted operation. The apparatus was tested in the determination of Arrhenius plots of $\log \mu_{\max }$ against the reciprocal of absolute temperature for a strain of Saccharomyces cerevisiae and a respiratory-deficient mutant prepared from it.
\end{abstract}

\section{INTRODUCTION}

The specific growth rate of a microbial population is a function of the concentration of the limiting substrate. The relationship found between specific growth rate and limiting substrate concentration often approximates to the Michaelis-Menten equation of unidirectional rates of enzyme reactions, although exceptions have been found (Droop, I968; Wu, Lin \& Tanaka, I968). In a chemostat the dilution rate controls growth rate by influencing the level of limiting substrate within the culture vessel (Monod, 1950; Novick \& Szilard, I950; Herbert, Elsworth \& Telling, I956). For maintaining fixed specific growth rates near the maximum specific growth rate $\left(\mu_{\max }\right)$ of the organism the chemostat is inadequate because the effect of substrate concentration on the specific growth rate tends to zero as saturating levels are approached. In a turbidostat, on the other hand, the organism concentration is controlled directly by a photo-electric sensor, therefore its operation is most successful close to the $\mu_{\max }$ where the organism concentration changes rapidly with dilution rate (Herbert, 1958). If all components of the medium are present in sufficient excess a turbidostat may be operated over a wide range of organism concentrations while still maintaining virtually $\mu_{\max }$.

Long term reliability of the turbidostat is generally poor: whether turbidity is measured directly within the culture vessel using very low organism concentrations (Bryson \& Szybalski, I952; Anderson, 1953) or by recycling some of the suspension through an external photoelectric sensing device (Cook, I95I; Moss, I956), wall growth soon leads to erroneous photoelectric detection. In efforts to overcome this problem, culture vessels have been fitted with 'windscreen wipers' (Northrop, I954; Anderson, 1956), and external detectors have been periodically flushed with sodium hydroxide followed by sterile water without dismantling the optical cell (Herbert, Phipps \& Tempest, 1965). 
In the present paper a new method is described in which the population may be held almost indefinitely at $\mu_{\max }$ through control of carbon dioxide production.

\section{THEORY}

The rate of production of $\mathrm{CO}_{2}$ by a growing population, $x$, is given by

$$
\frac{d \mathrm{CO}_{2}}{d t}=\frac{d x}{d t} \frac{1}{Y_{\mathrm{Co}_{2}}}
$$

where $Y_{\mathrm{Co}_{2}}$ is the yield factor with respect to carbon dioxide $(d x) /\left(d \mathrm{CO}_{2}\right)$.

The rate of production of organisms is a function of the population density, $d x / d t=\mu x$, where $\mu$ is the specific growth rate. It follows that

$$
\frac{d \mathrm{CO}_{2}}{d t}=\frac{\mu x}{Y_{\mathrm{Co}_{2}}} \text {. }
$$

Consider a batch culture containing a small inoculum growing without substrate limitation and consequently at $\mu_{\max }$. The rate of production of $\mathrm{CO}_{2}$ will increase as the organism concentration increases. Later, however, the concentration of at least one substrate becomes limiting, causing the specific growth rate to fall, eventually reaching zero upon exhaustion of substrate. Thus, after having reached a maximum and despite a further small increase in $x$ the product $\mu x$ will fall. Any of these transient states may be maintained as a steady state by transforming the system into a continuous culture and supplying fresh medium at a dilution rate equal to the specific growth rate at the transient state (Herbert, 1958). There are therefore two values of $\mu$ (and of $x)$ which experimentally satisfy equation 2 for any value of $\left(d \mathrm{CO}_{2}\right) /(d t)$ except the maximum value. These values may be predicted using equations of Monod (1950) and Herbert (1958) for substituting $\mu$ or $x$ in equation 2 and the following equation may be derived:

$$
\left(S_{r}+K_{s}\right) \mu^{2}-\left(\frac{d \mathrm{CO}_{2}}{d t} \frac{Y_{\mathrm{Co}_{2}}}{Y_{s}}+\mu_{\mathrm{max}} S_{r}\right) \mu+\frac{d \mathrm{CO}_{2}}{d t} \frac{Y_{\mathrm{CO}_{2}}}{Y_{s}} \mu_{\max }=0
$$

where $S_{r}$ is the concentration of limiting substrate in the inflowing medium, $K_{s}$ is a saturation constant, numerically equal to the substrate concentration at which the growth rate is one half of the maximum, $Y_{s}$ is the yield factor with respect to limiting substrate.

This equation can only be an approximation as $Y_{\mathrm{Co}_{2}}$ and $Y_{8}$ are not generally constant for wide ranges of specific growth rates (Herbert, 1958). Furthermore, the dependence of $\mu$ on $S$ does not necessarily obey the unidirectional Michaelis-Menten kinetics implied by the Monod equation (van Uden, $1967 b$ ) although good agreement has been obtained with a glucose-limited respiratory-deficient mutant of Saccharomyces cerevisiae IGC 3507 (van Uden, 1967a). For this yeast, the graph shown in Fig. I may be obtained. In the present study only values of $\left(d \mathrm{CO}_{2}\right) /(d t)$ corresponding to $\mu_{\max }$ were used.

\section{METHODS}

The problem is to maintain a constant rate of $\mathrm{CO}_{2}$ production by the culture. This rate, in an open system, is proportional to the concentration, in the outflowing gas phase, of $\mathrm{CO}_{2}$ produced by the culture $\left[\mathrm{CO}_{2}\right]$. and to the flow rate of the gas phase (air and $\mathrm{CO}_{2}$ ) out of the vessel, $f_{g}$

$$
\frac{d \mathrm{CO}_{2}}{d t}=\left[\mathrm{CO}_{2}\right] f_{\sigma}
$$


The design of the apparatus is shown in Fig. 2 and 3. The essential features were a means of supplying a constant flow of air to the culture vessel and an accurate device for measuring $\mathrm{CO}_{2}$ concentrations which, in conjunction with a controller unit, regulated the supply of culture medium into the culture vessel through a medium metering pump.

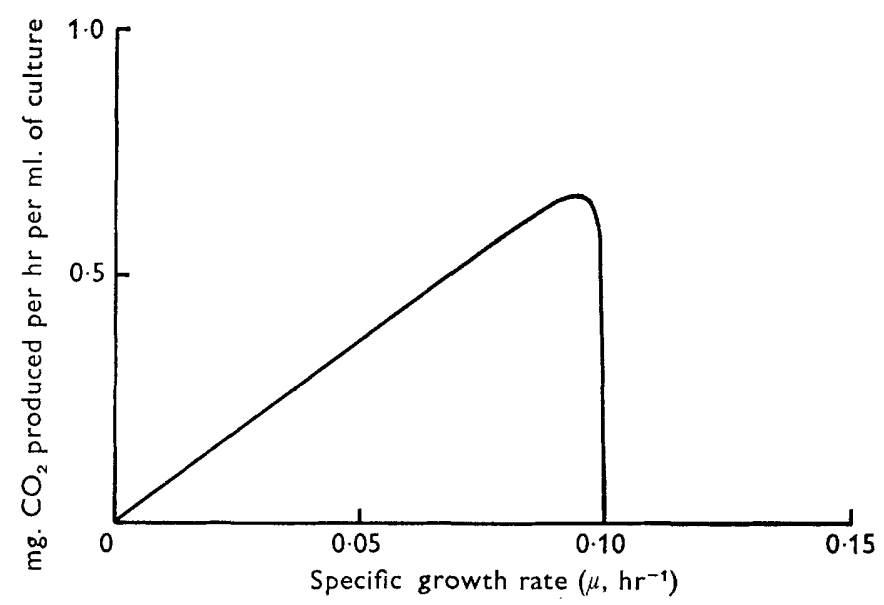

Fig. I. Theoretical relationship between growth rate $\left(\mathrm{hr}^{-1}\right)$ and carbon dioxide production (mg. $\mathrm{CO}_{2} / \mathrm{hr} / \mathrm{ml}$. culture) for a respiratory-deficient mutant of Saccharomyces cerevisiae I.G.C. 3507 using the following approximate values at $20^{\circ}, Y_{\mathrm{CO}_{2}}=0.4, Y_{s}=0 . \mathrm{I}, K_{s}=0.1 \mathrm{mg}$. glucose/ $\mathrm{ml}$., $S_{r}=30 \mathrm{mg}$. glucose $/ \mathrm{ml}$., $\mu_{\max }=0 . \mathrm{I} \mathrm{hr}^{-1}$ and calculated from equation 3.

The air supply from a compressor was controlled and stabilized using a Constant Differential Flow Controller (Model 63, Associated Electrical Industries Limited, Harlow, Essex, England). Before reaching the culture vessel the air was washed and equilibrated in a chain of gas washing bottles and passed through a sterile cotton wool filter. Two gas streams left the culture vessel. One carried with it spent culture into the receiver and the other, travelling through neoprene tubing (impermeable to air) passed through a sterile cotton wool filter, was dried in a silica-gel column and entered an infra-red carbon dioxide analyser (M.S.A. Lira Infra-red Analyser Model 300 , Mine Safety Appliances Company, Glasgow, E.3, Scotland). Both gas streams were later combined and the total gas flow measured using a 'Wet Test' gas meter (Precision Scientific Company, Chicago, Illinois, U.S.A.).

A continuous culture vessel of working volume I $60 \mathrm{ml}$. (New Brunswick Scientific Company, New Jersey, U.S.A.) was used with a gas flow rate of $750 \mathrm{ml} . / \mathrm{min}$. of which about $600 \mathrm{ml} . / \mathrm{min}$. passed through the $\mathrm{CO}_{2}$ analyser. The gas flow rates were controlled by two needle valves; the $\mathrm{CO}_{2}$ analyser was relatively insensitive to changes in gas flow rate between 500 and $2000 \mathrm{ml} . / \mathrm{min}$.

The output signal from the $\mathrm{CO}_{2}$ analyser (o to $\mathrm{Io} \mathrm{mV}$.) was directly proportional to $\mathrm{CO}_{2}$ concentration between $\mathrm{O}$ and $\mathrm{I} \% \mathrm{CO}_{2}$. The signal was led into an electronic controller unit (Witronic Controller, N.V. Philips, Gloeilampenfabriken, Eindhoven, The Netherlands), range set to accept input signal between 0 and $10 \mathrm{mV}$. A set-value was chosen to give the concentration of $\mathrm{CO}_{2}$ required in the effluent gas from the culture vessel and the controller linked in a conventional way with the on/off func- 
tioning of a peristaltic medium metering pump (Flow Inducer Type MHRE, WatsonMarlow Limited, Marlow, Buckinghamshire, England) so that it was actuated, when the $\mathrm{CO}_{2}$ concentration increased above the set value, to deliver medium at about twice the average steady state flow rate. As the organisms then washed out of the vessel, the population and rate of $\mathrm{CO}_{2}$ production fell. When the $\mathrm{CO}_{2}$ production dropped below the set-value the pump stopped. The apparatus could be run below the maximum specific growth rate (to the 'left' of the maximum $\mathrm{CO}_{2}$ output in Fig. I), if the controlling influence of change in $\mathrm{CO}_{2}$ concentration on the pump was reversed, such that $\mathrm{CO}_{2}$ concentrations above the set-value stopped and concentrations below actuated the pump. The medium pump was normally on and off for approximately 30 sec. each.

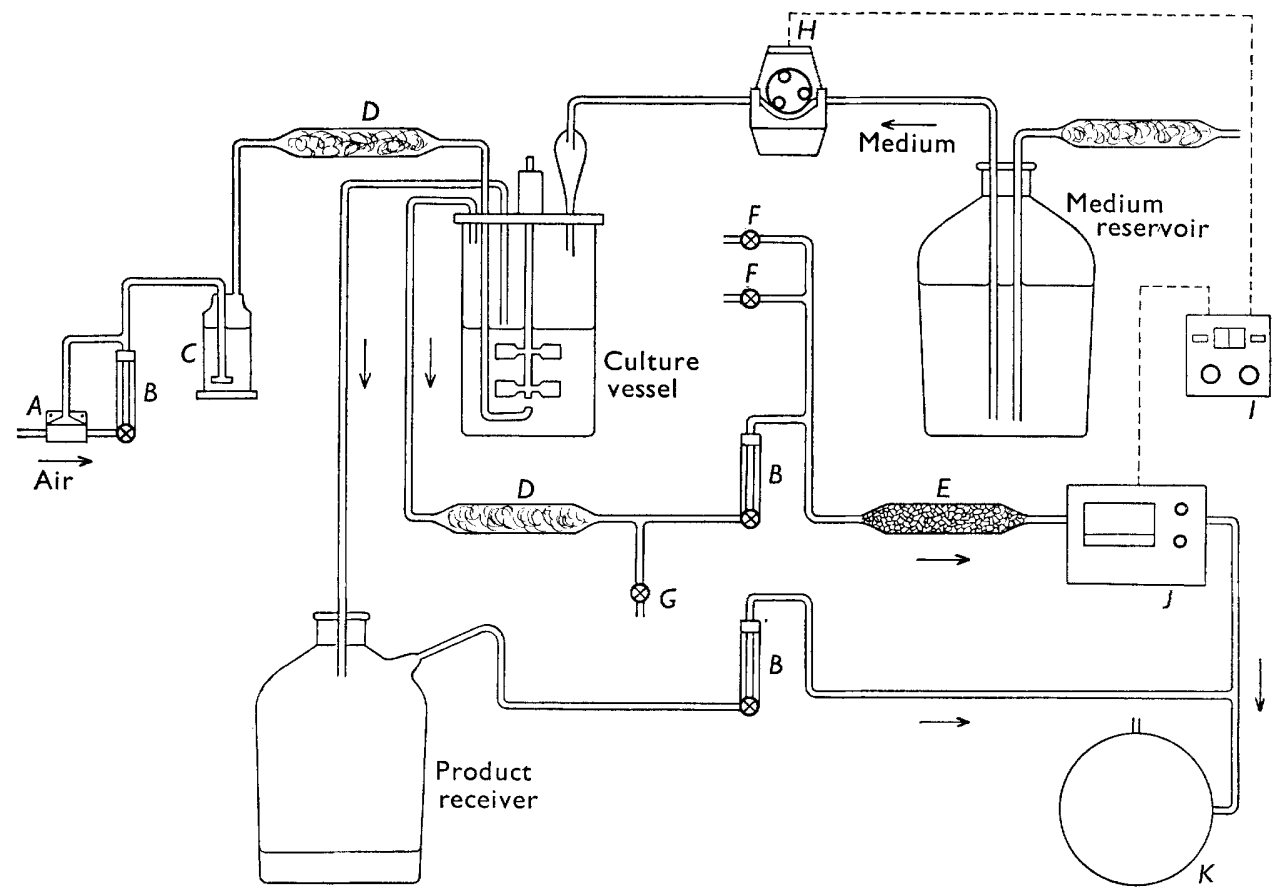

Fig. 2. Continuous culture apparatus. $A$, constant differential flow controller. $B$, flow meters with needle valves. $C$, gas-washing bottle with demineralized water. $D$, sterile cotton wool filters. $E$, silica gel column. $F$, inlet valves for calibration gases nitrogen $+\mathrm{I} \%(\mathrm{v} / \mathrm{v}) \mathrm{CO}_{2}$. $G$, bypass valve for outlet gas from culture vessel during calibration of $\mathrm{CO}_{2}$ meter. $H$, peristaltic medium metering pump. $I$, electronic controller unit. $J$, infra-red carbon dioxide analyser. $K$, 'Wet Test' gas meter. The culture vessel and gas-washing bottles were in a constant temperature water bath.

The culture medium was similar to that of van Uden ( $1967 a$ ) except that $3 \%$ glucose and an initial $\mathrm{pH}$ of 5.5 were used. The dilution rates and hence the specific growth rates were usually measured over approximately $20 \mathrm{hr}$ by collecting spent culture medium. Much shorter periods could be used when the pump delivery was known accurately and the pump was connected to an electrical timer, allowing average flow rates to be calculated over a few minutes. This was especially useful for verifying a new steady-state following a change in parameters. 
The apparatus was tested by determining $\mu_{\max }$ at different temperatures for $S a c$ charomyces cerevisiae IGC 3507 from the culture collection of this laboratory, and a respiratory-deficient mutant prepared from it by van Uden (1967a).

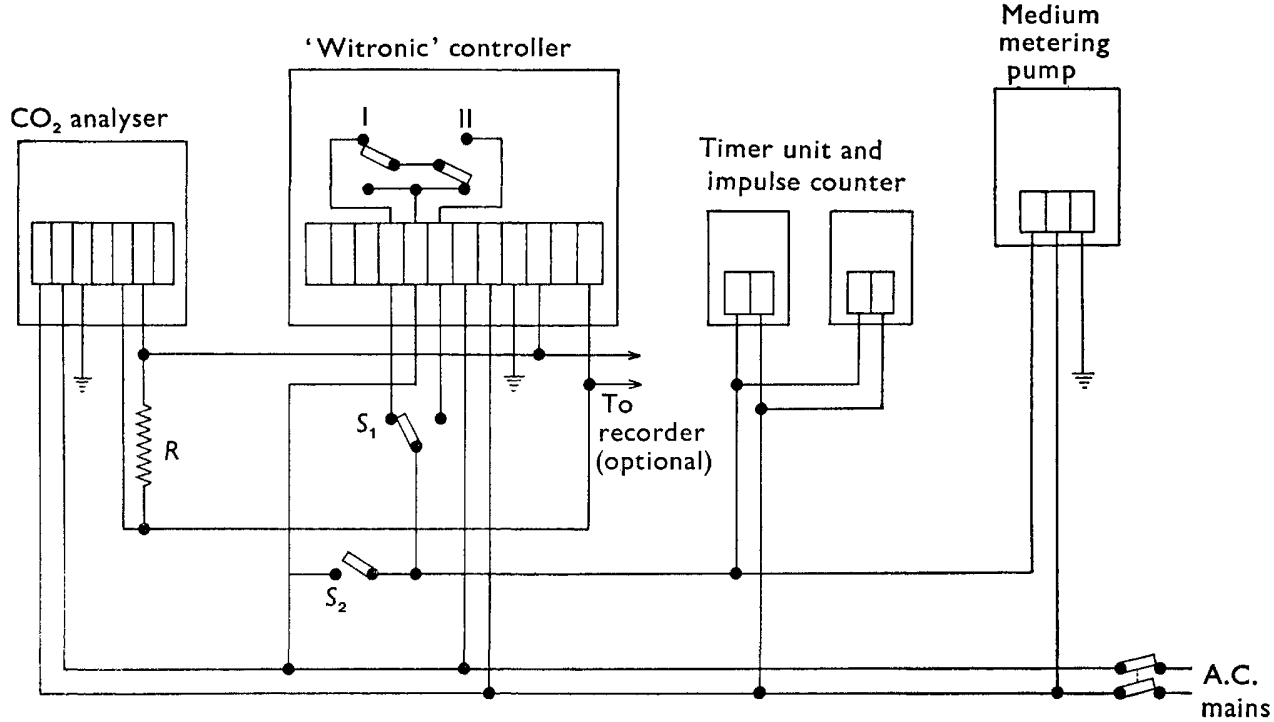

Fig. 3. Wiring diagram for operation of continuous culture apparatus through control of carbon dioxide production. The controller has two relays, I and II. In the diagram relay II is being used. To operate the medium pump when the $\mathrm{CO}_{2}$ production falls below the set value, relay I must be used in place of II by changing the position of switch $S_{1}$. Switch $S_{2}$ is normally in the open position. It may be closed to operate the medium pump manually and the system becomes a chemostat. A resistance, $R$, may be necessary to bring the output signal of the $\mathrm{CO}_{2}$ analyser into the input range of the controller.

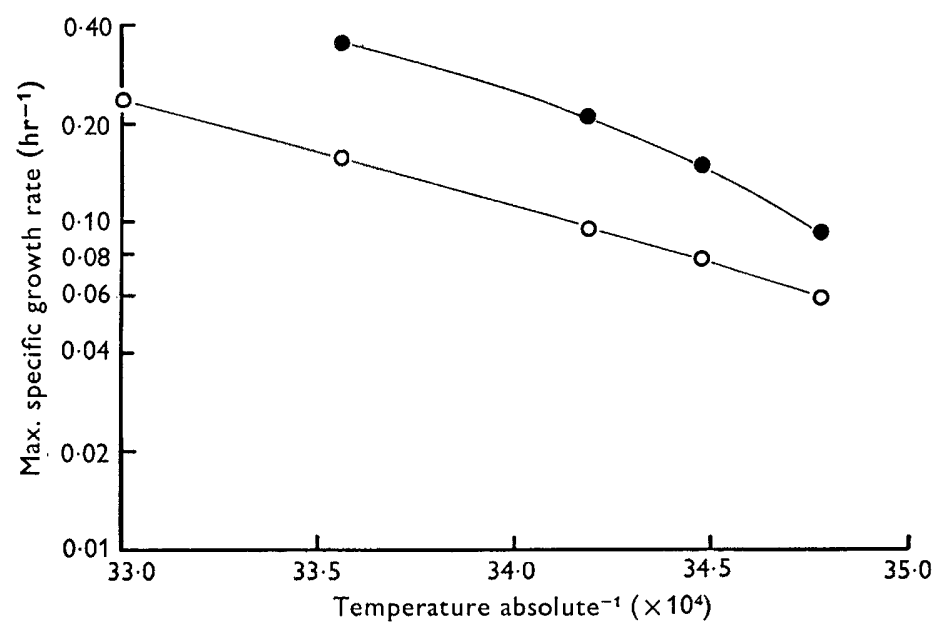

Fig. 4. The temperature dependence of the maximum specific growth rates of Saccharomyces cerevisiae I.G.C. $3507, \bullet$, and its respiratory-deficient mutant, $\bigcirc$, as Arrhenius plots. 


\section{RESULTS}

Table I lists $\mu_{\max }$ values between $14.5^{\circ}$ and $30^{\circ}$. The rate of production of $\mathrm{CO}_{2}$ was maintained at $0 \cdot 166 \mathrm{mg}$. $\mathrm{CO}_{2} / \mathrm{hr} / \mathrm{ml}$. culture at N.T.P. Cell concentrations and yield factors with respect to $\mathrm{CO}_{2}$ are included. Figure 4 shows the data as an Arrhenius plot.

Table I. Maximum specific growth rates, cell concentrations and yields with respect to $\mathrm{CO}_{2}$ of Saccharomyces cerevisiae IGC 3507 and a respiratory-deficient mutant at different temperatures in a $\mathrm{CO}_{2}$-controlled continuous culture apparatus

\begin{tabular}{|c|c|c|c|}
\hline $\begin{array}{l}\text { Temperature } \\
\left({ }^{\circ} \mathrm{C}\right)\end{array}$ & $\begin{array}{l}\text { Maximum specific } \\
\text { growth rate }\left(\mathrm{hr}^{-1}\right)\end{array}$ & $\begin{array}{l}\text { Organism concentration } \\
\mathrm{mg} \text {. dry wt } / \mathrm{ml} \text {. }\end{array}$ & $\begin{array}{l}\text { Yield }\left(\mathrm{CO}_{2}\right) \\
(\mathrm{w} / \mathrm{w})\end{array}$ \\
\hline \multicolumn{4}{|c|}{ Parent strain } \\
\hline $14 \cdot 5$ & $0.0936 \pm 0.0008(5)$ & $\mathrm{I} \cdot 0 \mathrm{I} 4 \pm 0.009(5)$ & 0.57 \\
\hline $17 \cdot 0$ & $0.149 \mathrm{I} \pm 0.001 \mathrm{I}(3)$ & $0.616 \pm 0.007$ & 0.55 \\
\hline $19 \cdot 5$ & $0.2128 \pm 0.0010$ & $0.426 \pm 0.005(4)$ & 0.55 \\
\hline $25 \cdot 0$ & $0.3575 \pm 0.0020(3)$ & $0.338 \pm 0.010$ & $0 \cdot 73$ \\
\hline \multicolumn{4}{|c|}{ Mutant strain } \\
\hline $14 \cdot 5$ & $0.0590 \pm 0.0009$ & $I \cdot 057 \pm 0.020(4)$ & 0.38 \\
\hline $17 \cdot 0$ & $0.0773 \pm 0.0009$ & $0.845 \pm 0.014$ & 0.39 \\
\hline $19 \cdot 5$ & $0.0954 \pm 0.0009(5)$ & $0.659 \pm 0.014(5)$ & 0.38 \\
\hline $25 \cdot 0$ & $0.1580 \pm 0.0009(4)$ & $0.404 \pm 0.009(4)$ & 0.39 \\
\hline $30 \cdot 0$ & $0.2378 \pm 0.0012(3)$ & $0.250 \pm 0.008$ & 0.36 \\
\hline
\end{tabular}

\section{DISCUSSION}

Table I shows that $\mu_{\max }$ could be determined with a high degree of precision. The method was applied to both the anaerobic (the respiratory-deficient mutant) and the aerobic organism. The $Y_{\mathrm{Co}_{2}}$ increased under conditions of aerobic metabolism.

Unlike the situation in a turbidostat, the organism concentration was not constant at different specific growth rates. The reason is easily seen by rearranging equation 2

$$
x=\frac{Y_{\mathrm{Co}_{2}}}{\mu} \frac{d \mathrm{CO}_{2}}{d t} .
$$

Changes in $Y_{\mathrm{Co}_{2}}$ were small over the range of growth rates studied for each strain, so changes in $\mu_{\max }$ must have been compensated for by changes in organism concentration to maintain $\left(d \mathrm{CO}_{2}\right) /(d t)$ constant. For the aerobic yeast, the higher $Y_{\mathrm{Co}_{2}}$ leads to higher organism concentrations for any value of $\mu$.

The method has been operated on several occasions for more than I month. The only adjustments required were daily 'zero-ing' of the $\mathrm{CO}_{2}$ analyser with nitrogen gas and weekly adjustment of the 'span' control with $\mathrm{I} \% \mathrm{CO}_{2}$; these operations took only a few minutes. A slight periodic adjustment was required in the rate of air supply to maintain a constant relation between $\mathrm{CO}_{2}$ concentration in the outflowing gas and rate of $\mathrm{CO}_{2}$ production. The apparatus therefore offers advantages over turbidostatic methods, especially when long term operation is required. It has the additional advantage of being easily assembled from commercially available units of equipment. 
The author would like to record his thanks to Dr N. van Uden for his continued interest and constructive suggestions, to $\mathrm{Sr} \mathrm{A}$. J. H. Tezinho for valuable technical advice and to the Calouste Gulbenkian Foundation, Lisbon (United Kingdom and British Commonwealth Branch), for a grant which made this work possible.

\section{REFERENCES}

ANDERSON, P. A. (1953). Automatic recording of the growth rates of continuously cultured microorganisms. J. gen. Physiol. 36, 733.

Anderson, P. A. (1956). Continuous recording of the growth of micro-organisms under turbidostatic and chemostatic control. Rev. scient. Instrum. 27, 48.

Bryson, V. \& SZYBalski, W. (1952). Microbial selection. Science, N.Y. Ir6, 45.

CoOK, P. M. (I95I). Chemical engineering problems in large scale culture of algae. Ind. Engng. Chem. 43, 2385 .

Droop, M. R. (1968). Vitamin $B_{12}$ and marine ecology. IV. The kinetics of uptake, growth and inhibition in Monochrysis lutheri. J. mar. biol. Ass. U.K. 48, 689.

Herbert, D. (1958). Some principles of continuous culture. Int. Congr. Microbiol. No. 7 (Stockholm), p. 372 .

Herbert, D., Elsworth, R. \& Telling, R. C. (1956). The continuous culture of bacteria: a theoretical and experimental study. J. gen. Microbiol. 14,60I.

Herbert, D., Phipps, P. J. \& Tempest, D. W. (1965). The chemostat: design and instrumentation. Lab. Pract. 14, I 150.

Monod, J. (1950). La technique de culture continue; théorie et applications. Annls Inst. Pasteur 79, 390.

Moss, F. (1956). Adaptation of the cytochromes of Aerobacter aerogenes in response to environmental oxygen tension. Aust. J. exp. Biol. med. Sci. 34, 395.

NoRTHROP, J. H. (1954). Apparatus for maintaining bacterial cultures in the steady state. J. gen. Physiol. 38, 105.

Novick, A. \& SZILARD, L. (I950). Description of the chemostat. Science, N.Y. II2, 715.

VAN UDEN, N. (1967a). Transport-limited fermentation and growth of Saccharomyces cerevisiae and its competitive inhibition. Arch. Mikrobiol. 58, 155.

vaN UdEN, N. (1967b). Transport-limited growth in the chemostat and its competitive inhibition; a theoretical treatment. Arch. Mikrobiol. 58, 145.

Wu, T. T., Lin, C. C. \& TANAKA, S. (I968). Mutants of Aerobacter aerogenes capable of utilizing xylitol as a novel carbon. J. Bact. 96,447 . 